\title{
Schmooze or Lose: Social Friction and Lubrication in E-Mail Negotiations
}

\author{
Michael Morris \\ Stanford University and Columbia University
}

\author{
Janice Nadler, Terri Kurtzberg, and \\ Leigh Thompson \\ Northwestern University
}

\begin{abstract}
Past research has indicated that rapport helps negotiators overcome interpersonal friction and find cooperative agreements. Study 1 explored differences in the behavioral dynamics evoked by e-mail versus face-to-face negotiation. Although some behavioral content categories differed in ways pointing to strengths of e-mail, the strongest pattern was that e-mail inhibited the process of exchanging personal information through which negotiators establish rapport. The authors hypothesized that the liabilities of e-mail might be minimized by a pre-negotiation intervention of social lubrication. To test this in Study 2, half of dyads had a brief personal telephone conversation ("schmoozed") before commencing e-mail negotiations, and half did not. Schmoozers felt more rapport, their plans were more trusting (although no less ambitious), and their economic and social outcomes were better.
\end{abstract}

E-mail and other Internet-enabled communications technologies are increasingly relied on to negotiate everyday conflicts with coworkers as well as contracts with strangers (for reviews, see Schrage, 1995; Thompson, 2001). This dramatic change in the texture of organizational communications - and the salient positive and negative experiences that individuals have when trying to negotiate deals or disputes via e-mail-have sparked popular writings about how the dynamics of dyadic and group interaction hinge on communication media (e.g., Kiser, 1999; Seaberry, 2000). Yet scientific research on the basic question of how e-mail and face-to-face negotiations differ is sparse. There

\footnotetext{
Michael Morris, Graduate School of Business, Stanford University, and Graduate School of Business, Columbia University; Janice Nadler, School of Law, Northwestern University; Terri Kurtzberg and Leigh Thompson, Kellogg Graduate School of Management, Northwestern University.

We thank Kip Williams and two anonymous reviewers for helpful comments and the Stanford Graduate School of Business, where Michael Morris worked at the start of this research, and the Dispute Resolution Center at Northwestern University for financial, logistical, and administrative support.

Correspondence concerning this article should be addressed to Michael Morris, Graduate School of Business, Columbia University, 708 Uris Hall, 3022 Broadway, New York, New York 10027-6902. E-mail: mwm82@ columbia. edu Web site: http://www.michaelwmorris.com
}

is even less research about the equally important question of how the strengths and liabilities of e-mail depend on how it is used. Because uses of technologies evolve over time, it would be a mistake to assume that the social dynamics associated with e-mail are inevitable byproducts of inherent properties of the technology. We review past research and then present an initial study exploring how the content of negotiation differs between the e-mail and face-to-face media. We hypothesize that the liabilities of e-mail negotiation can be minimized through "social lubrication," a brief pre-negotiation interaction structured to establish personal exchange.

\section{Past Research Relevant to E-Mail Negotiation}

In the tradition of research on media effects in negotiation (Poole, Shannon, \& DeSanctis, 1992), several research groups have examined whether e-mail differs from face-to-face communication in producing negotiation outcomes of high mutual value. Evidence is mixed. One study finds an advantage of e-mail (Purdy, Nye, \& Balakrishnan, 1997). One finds a disadvantage (Arunachalam \& Dilla, 1995). And three find no significant difference between the media (Barsness \& Tenbrunsel, 1998; Croson, 1999; Rangaswamy \& Shell, 1997). These mixed findings suggest that e-mail may affect negoti- 
ations in more than one way or that the problematic dynamics associated with e-mail may arise only in certain kinds of negotiation problems.

Observational studies (see review by Morris $\&$ Keltner, 2000) have suggested that negotiation dyads rely on social emotions to overcome obstacles such as initial mistrust and interpersonal friction. Negotiators establish a basis of trust with a set of verbal and nonverbal behaviors that communicate openness (handshakes, open-palmed gestures, disclosures of personal non-task-relevant information) and interest (smiles, nodding, questions about the other). Negotiators repair a relationship after friction with displays such as deference or embarrassment to appease an irritated opponent. These displays are largely automatic, habitual behaviors, not self-consciously enacted performances.

One way that media influence negotiations is by facilitating or inhibiting the communication of personal, emotional messages through verbal and nonverbal exchanges. This can be illustrated clearly in research on the synchrony of nonverbal emotional expressions, which is an antecedent of dyadic and group rapport (TickleDegnen \& Rosenthal, 1987) and is independent of the verbal dynamics, such as mutual selfdisclosure, that also work to create rapport (Poole, Folger, \& Hewes, 1987). A study comparing telephone with face-to-face conflict resolution found that synchrony of nonverbal displays between the two negotiators was the critical difference between the two conditions in accounting for the higher rate of high joint gain outcomes in the face-to-face condition (Drolet \& Morris, 2000, Experiment 2). E-mail, of course, provides significantly less access to nonverbal emotional cues than does the telephone, which at least provides aural cues. Moreover, many of the verbal behaviors that come as part of the scripted greeting ritual in face-toface interaction (self-disclosure, small talk, personal questions) may be less likely in an e-mail encounter. Hence, to the extent that rapport is needed to get negotiators through the friction, e-mail negotiators may suffer from its deficit.

\section{Study 1}

Our first study was an experiment in which dyads negotiated through either e-mail or faceto-face communication. Our goal was to explore differences among e-mail and face-to-face communication. Transcripts of the negotiation sessions were content analyzed using a comprehensive coding scheme distinguishing types of information disclosures, questions, persuasion tactics, offers, and statements.

\section{Method}

Participants. A total of 78 full-time masters of management students from the Kellogg Graduate School of Management participated as part of a classroom exercise on negotiation.

Design. The single independent variable was between subjects and had two levels: Email versus face-to-face communication media. Two classes negotiated via e-mail and two classes negotiated face-to-face. There were a total of 16 face-to-face dyads and 23 e-mail dyads.

Procedure. In both conditions, participants read materials in class prior to the actual negotiation to prepare for their role in the exercise. The negotiation exercise is a two-party negotiation that includes incentives to cooperate as well as to compete (Bazerman \& Brett, 1997). Parties were motivated both to claim as much value for themselves as possible and to maximize the overall value of the deal. The value of all possible outcomes to each party is specified by a formula in the case, including the value of impasse outcomes.

In the e-mail condition, participants were given the name and e-mail address of their opponent ${ }^{1}$ and were instructed to conduct their negotiation entirely through e-mail messages. They were instructed to complete the negotiation within 3 days. If no agreement was reached by the deadline, the negotiation was declared an impasse. In the face-to-face condition, negotiations took place within a fixed time period, at the end of which either parties had reached mutual agreement or an impasse was declared. Face-to-face negotiations were audiotaped and then transcribed, so as to allow comparisons to the e-mail transcripts.

Content analysis of negotiator statements. Transcripts of negotiation sessions were segmented into units at the level of discrete state-

\footnotetext{
${ }^{1}$ The term opponent is used for clarity here but was not used in any of the materials.
} 
ments or thoughts (usually each sentence was coded as one thought, unless the sentence was long and complex). A categorization scheme, adapted from a previous content analysis study by Weingart, Thompson, Bazerman, and Carroll (1990), comprised four major categories, each with several subcategories. The first major category was information exchange and included revelations and questions. The second category was persuasion tactics, under which we distinguished promises (descriptions of positive consequences to follow) from threats (descriptions of the negative consequences to follow if an offer were rejected or concession refused). The third category was offers (single-issue, multiissue, or final ultimatum). The final category was metalevel statements about the negotiation, which included several kinds of statement that have been less salient in past studies of face-toface negotiation.

All units in negotiation transcripts were categorized by two trained judges who were naive to the experiment's purpose and hypotheses. They agreed on $80 \%$ of the items and resolved all disagreements after brief discussion.

\section{Results and Discussion}

We first describe differences between e-mail (EML) and face-to-face (FTF) negotiators in the proportional frequency of particular behaviors. Then we describe differences between conditions in which behaviors were efficacious (in that their frequency was predictive of an outcome high in joint profits).

Frequency differences. The number of lines in each message was used as a means of standardization so the proportional frequency of particular statements could be compared, as shown in Table $1 .^{2}$ In the first category, information exchange, a striking pattern appears in the frequency with which different kinds of information were revealed. Whereas EML and FTF negotiators did not differ with regard to sharing information about preferences, reservation prices, best alternatives to a negotiated agreement), or priorities with regard to multiple issues or in their likelihood of making unilateral concessions, EML negotiators disclosed only one third as much about nonnegotiation issues. These non-task-relevant disclosures may have come less naturally in an EML than a FTF encounter. Likewise, with regard to questions asked, EML negotiators were only a fifth as likely to query their opponent about topics other than the negotiable issues. But the inhibition in question asking among EML negotiators also extended to questions about preferences and especially to questions of clarification. Apparently EML exchange does not lend itself to frequent questioning, perhaps because it is hard to exchange the paralinguistic cues with which questions are invited in FTF conversations. ${ }^{3}$ Overall, the differences in information exchange suggest that the normal ways of building rapport-through exchanges of personal emotional disclosures in a dynamic involving feedback and coordination of behavior-are inhibited in an e-mail interaction.

There were no differences as a function of media in the persuasion tactics category. In the category of offers, there was one striking difference consistent with the claims about the capacity of e-mail as a medium for conveying complex information, namely, that offers involving multiple issues were proposed 12 times more frequently by EML than FTF negotiators. Within the residual category of metalevel statements there were several significant differences. Explicit statements about building or maintaining a relationship with one's opponent were made far more frequently by EML negotiators.

\footnotetext{
${ }^{2}$ Given that our interest lay in how media differentially evoke particular kinds of statements and that our study did not control the length of e-mail negotiation sessions, we controlled for the absolute number of statements and focused on the proportional frequency of different kinds of statements. The absolute number of statements made with each medium might also be an interesting question, but it is not one our study lent itself to given that the time periods were not constrained in the same way across conditions. The total volume of communication was greater in the face-toface negotiations: FTF dyads averaged 487.25 lines of transcribed text, whereas EML dyads averaged only 133.83 lines, $t(37)=8.30, p<.001$. FTF negotiators exchanged more messages $(M=346.37$ vs. $M=10.39), t(37)=$ $-9.96, p<.001$, yet these FTF messages were shorter in length $(M=1.44$ lines of transcript per speaking turn vs. $M=12.68$ lines per turn in e-mails), $t(37)=10.96, p<$ .001. Proportional frequency scores were created by dividing the frequency with which particular kinds of behavioral content occurred in a transcript by lines of text.

${ }^{3}$ Another possibility suggested by a reviewer is that information in EML communication is so clear and ample that no questions need to be asked. However, this interpretation cannot stand up to the revelation results, which show that so little information is conveyed by EML negotiators about task-nonrelevant issues.
} 
Table 1

Proportional Frequency of Negotiation Behaviors Under E-Mail and Face-to-Face Conditions (Study 1)

\begin{tabular}{|c|c|c|c|}
\hline Behavior variable & $\begin{array}{c}\text { E-mail } \\
(n=23)\end{array}$ & $\begin{array}{c}\text { Face-to-face } \\
\quad(n=16)\end{array}$ & $t$ \\
\hline \multicolumn{4}{|l|}{ Information exchanged } \\
\hline \multicolumn{4}{|l|}{ Revelations } \\
\hline Preference & 8.15 & 7.61 & 0.253 \\
\hline Reservation price & 1.01 & 0.626 & 1.36 \\
\hline BATNA & 0.779 & 0.563 & 0.848 \\
\hline Multiple issues & 0.24 & 0.126 & 0.914 \\
\hline Nonnegotiable issue & 10.31 & 34.63 & $-10.74 * * *$ \\
\hline Unilateral concession & 0.028 & 0.025 & 0.076 \\
\hline \multicolumn{4}{|l|}{ Questions } \\
\hline Preference & 1.86 & 4.50 & $-4.05 * * *$ \\
\hline Nonnegotiable issue & 0.76 & 4.84 & $-8.28 * * *$ \\
\hline Clarification & 0.46 & 6.72 & $-10.48^{* * *}$ \\
\hline \multicolumn{4}{|l|}{ Persuasion tactics } \\
\hline Benefit to you & 10.53 & 13.07 & -1.16 \\
\hline Threat & 0.28 & 0.035 & 1.23 \\
\hline \multicolumn{4}{|l|}{ Offers made } \\
\hline Single issue & 2.59 & 1.32 & $2.02 \dagger$ \\
\hline Multiple issue & 6.01 & 0.45 & $5.00 * * *$ \\
\hline Final & 0.66 & 0.013 & 1.6 \\
\hline \multicolumn{4}{|c|}{ Metalevel statements about the negotiation } \\
\hline \multicolumn{4}{|c|}{ About one's goals } \\
\hline Value creating & 0.80 & 0.74 & 0.277 \\
\hline Value claiming & 0.017 & 0.012 & 0.216 \\
\hline \multicolumn{4}{|l|}{ About the relationship } \\
\hline Building & 10.56 & 1.51 & $7.46^{* * *}$ \\
\hline Maintain & 6.82 & 4.31 & $2.73 * *$ \\
\hline Personalize self & 2.04 & 2.11 & 0.052 \\
\hline Reminder of role obligations & 0.59 & 0.043 & $1.91 \dagger$ \\
\hline About the agenda: Procedural & 11.44 & 4.31 & $5.13 * * *$ \\
\hline
\end{tabular}

Note. BATNA $=$ best alternative to negotiated agreement.

$\dagger p<.10$ (marginally significant). $* p<.05 . \quad * * p<.01 . \quad * * * p<.001$.

Although at first glance, this may seem incongruent with the lower level of personal disclosure and information seeking by EML negotiators, it very likely reflects a compensatory effort. Because it is difficult for EML negotiators to engage in rapport-building paralinguistic behaviors that come naturally in FTF conversation, they compensate by making explicit statements about the relationship-statements that most likely would seem superfluous in a FTF conversation. The final difference observed, in statements about the agenda or procedure, also seems to be a matter in which EML negotiators resort to explicit statements to convey messages that might be conveyed by expressions or actions in a FTF encounter.

Efficacy differences. The joint profit scores for EML negotiators $(M=13.87)$ and FTF negotiators $(M=14.68)$ did not significantly differ, $t(37)=-1.15, p=.13$. Yet differences in which behaviors were associated with success within each condition suggest strategies that are context dependent. We examined this descriptively in the bivariate correlations of frequency scores and joint profit within each condition, and we tested for differential efficacy by regressing joint profit on a term capturing the interaction of media and a given frequency score. ${ }^{4}$ Only 3 of the 21 behavior scores proved to be differentially predictive as a function of media, and these 3 findings tell a common story. The use of threats as a persuasion tactic was

\footnotetext{
${ }^{4}$ The dummy variable was constructed such that e-mail $=1$ and face-to-face $=-1$.
} 
much more damaging to the attainment of mutually beneficial outcomes in the EML condition, $r(23)=-.96, p<.001$, than in the FTF condition, $r(16)=-.29, n s$. In the regression, the interaction of threat frequency with media condition was highly significant $(\beta=3.38, p<$ .001). Similarly, the use of final, ultimatum offers was more damaging in the EML condition, $r(23)=-.43, p<.05$, than in the FTF condition, $r(16)=-.35, n s$. (interaction term $\beta=0.77, p<.01)$. Finally, statements explicitly referring to the other person's obligations were damaging in the EML condition, $r(23)=$ $-.52, p<.05$, but not in the FTF condition, $r(16)=.21, n s$ (interaction term $\beta=1.29, p<$ .001). These three findings all attest to the greater fragility of trust in EML interactions; whereas FTF negotiators got beyond the difficult moments created by these somewhat contentious tactics, EML negotiators fell into a downward spiral of decreased cooperation.

From exploring media effects to testing interventions. Our first study explored the general differences in behavioral content of EML and FTF negotiations. EML fostered the exchange of complex offers, yet it did not result in better outcomes. EML inhibited the exchange of personal information and the asking of questions. EML negotiators were more inclined to explicit avowals of the importance of the relationship; telling each other rather than showing each other that a relationship existed. In any case, EML negotiations were vulnerable to trust breakdowns after contentious tactics. Our interpretation is that EML negotiations suffered from low levels of rapport.

Is it worth asking whether there is a way of using e-mail that allows negotiators to reap its advantages without running its risks? In a first take on this question, a study by Moore, Kurtzberg, Thompson, and Morris (1999) examined whether instructing EML negotiators to share personal information affected rapport and, ultimately, negotiated outcomes. As in Study 1, Moore et al. used a task in which it is relatively easy for negotiators to find an agreement better than their respective alternative options. Another aspect of Study 1 that contributed to the cooperative orientation is the fact that dyads comprised students from the same negotiation class. Moore et al. manipulated in-groups and out-groups: In the in-group condition, dyads comprised students from the same business school; in the out-group condition, dyads comprised students from different business schools. This in-group/out-group manipulation was crossed with a social lubrication manipulation: whether negotiators were told to exchange personal information and ask personal questions in a series of initial e-mails before turning to the negotiable issues.

Results of the Moore et al. (1999) study provided mixed support for the social lubrication interpretation. Rapport was measured in a postnegotiation questionnaire, and the lubrication manipulation increased the level of rapport. Unexpectedly, so did the in-group manipulation. An appreciable fraction of the dyads ended with the outcome of impasse, and hence impasse rate was the key economic outcome variable. Yet because the negotiation task was generally oriented toward cooperation, the impasse rate variable suffered from a floor effect. Whereas roughly a third of dyads in the no-lubrication/ out-group cell ended in impasse, in the other conditions there were only one or two dyads that ended in impasse. This creates interpretational ambiguity. Moore et al. conducted post hoc analyses contrasting the no-lubrication/outgroup cell with the other three cells and found the difference in impasse rate was statistically mediated by the difference in affective rapport. Yet because the analysis was conducted with a postnegotiation measure of rapport, which may have been affected by the experience of impasse, the authors acknowledge that the direction of causality is "indeterminate" (Moore et al., 1999, p. 39).

Overall, the Moore et al. (1999) study is consistent with the lubrication hypothesis but does not provide conclusive findings. To test the prophylactic power of social lubrication, we chose to study negotiations in which the problematic EML dynamic of escalating interpersonal friction has a strong effect on outcomes. Given that the level of rapport in the Moore et al. study was lower in the out-group condition, it seemed best to focus Study 2 on an out-group context: a negotiation between strangers. Furthermore it follows that an interorganizational conflict would be better than a within-organizational conflict; the role of prior relationships in providing a basis of trust is minimized. Finally, a negotiation with a narrow bargaining zone should work better than one allowing an ample bargaining zone. A tight bargaining zone in- 
creases the level of haggling, the number of their demands refused and offers rejected, and ultimately the impression of one's uncooperativeness (Morris, Larrick, \& Su, 1999). The Moore et al. (1999) study also provides a lesson about outcome measures: Impasse rate, rather than joint profitability, seems to pick up e-mailinduced downward spirals of mistrust. Yet, given that the binary nature of the impasse variable limits its sensitivity, it is also wise to include direct measures of the social outcomefeelings, judgments, and expectations about the other person.

Another goal of the present study was to operationalize lubrication in a manner exogenous from the e-mail conversation. We manipulated whether opponents engaged in a personal chat on the telephone before initiating their EML negotiation. Instructions required speaking for $5 \mathrm{~min}$ only and not about the issues under negotiation. We hypothesized that this brief exchange of personal information, responsive questioning, and nonverbal cues of interest would inject rapport into an interaction and that this would have lasting consequences in helping negotiators ease through the friction of negotiation without sparks, flames, or conflagration.

\section{Study 2}

To test our social lubrication hypothesis, we had master's students in business school engage in an e-mail negotiation with students from a rival university. We varied whether students "schmoozed" on the telephone for 5 min before commencing the negotiation. We predicted that this brief schmoozing session, by lubricating the interaction with a level of interpersonal rapport, would improve the economic and social outcomes of negotiations, which were measured using questionnaires focusing on postnegotiation feelings, impressions, and expectations. We also measured the level of rapport at the start of the negotiation, which was expected to mediate the effect of the schmooze manipulation. Measures of negotiation plans were taken to test an alternative interpretation that schmoozing, a positive experience, simply increases positive expectancies about getting a better outcome.

\section{Method}

Participants. A total of 120 students participated in the study. All were full-time masters students in business school. Of the participants, half were students at Stanford University's Graduate School of Business, and the other half were students at the Kellogg Graduate School of Management at Northwestern University. The students participated in fulfillment of a class assignment in a negotiations course.

Design. We manipulated the presence or absence of a phone schmoozing session. We randomly assigned students to buyer and seller roles. We then constructed dyads by randomly assigning men to either male-male or malefemale roles (the low fraction of women preventing a female-female group). Within each dyad-gender-composition block, half of the dyads were randomly assigned to the schmooze conditions and half to the nonschmooze condition.

Procedure. Participants were instructed to conduct a two-party negotiation exclusively via e-mail. Each student received a packet of materials that contained a page of general confidential instructions and guidelines; an e-mail address for the opponent; pre- and postnegotiation questionnaires; and in the schmooze condition, additional personal information about the opponent, as described below. Participants were given 1 week to complete the negotiation and questionnaires.

Participants in the schmooze condition received two special instructions. First, in addition to their negotiating partner's name and e-mail address, each participant received a small, black-and-white photograph of their partner, accompanied by a few biographical details and a phone number, and they were instructed to have an initial "getting to know each other" telephone conversation with their partner before they began negotiating. Instructions required that participants not discuss negotiable issues or business on the phone but merely have a brief social conversation. All negotiation in both the schmooze and nonschmooze conditions took place via e-mail.

Negotiation task. Participants engaged in a negotiation involving the purchase of a new company car by a manager at a software company. The negotiation contained both distributive and integrative elements. To find a contract that would be better for both parties than their respective alternatives, negotiators had to find all of the ways possible to create value, which required information exchange and ultimately 
required that negotiators trust each other to be honest and open in disclosing information about priorities.

Pre-negotiation measures. Participants completed the pre-negotiation questionnaire, titled "Preparation Worksheet," after reading the negotiation case materials in both groups (and for the schmooze dyads, after the initial phone conversation), but prior to e-mail contact with the opponent. All participants completed a questionnaire about their feelings toward their opponent as well as their strategic plans for the negotiation. One set of questions asked negotiators to describe their "attitude" or "current state of mind" toward their opponent by rating seven feelings (competitive, cooperative, engaged, indifferent, open, positive, and sympathetic) on a 7 -point scale $(1=$ not at all; $7=$ quite a bit). Another set of questions asked negotiators to state in terms of points their reservation price and aspiration level. ${ }^{5}$

Postnegotiation measures. A second questionnaire, entitled "Diagnosis Worksheet," was completed after the negotiation. This postnegotiation questionnaire was distributed with the package of materials but was sealed separately, and participants were instructed not to open the seal on the postnegotiation questionnaire prior to completion of the negotiation. This contained several initial questions asking participants to assess their own performance and to report their estimates of their opponent's preferences on the issues, which were not relevant to the study. Following this were three sets of questions designed to tap different aspects of the social outcome. First, participants were asked to describe "feelings" toward their counterpart by rating a series of adjectives (angry, annoyed, cold, disappointed, friendly, frustrated, pleasant, positive, sensitive, and warm) on a 7-point scale $(1=$ not at all; $7=$ extremely $)$. Next, participants were asked about their perceptions of some general characteristics of the other person related to trustworthiness (deceptive, fair, secretive, selfish, sincere, and trustworthy) on a 7 -point scale $(1=$ not at all; $7=$ extremely). Finally, there were two scenario-based questions measuring expectations of one's future working relationship with the other person: "If you had to work on another project together, do you sense that it would go smoothly?" $(1=$ not at all; 7 = very much so); "Imagine that, in the future, you are in a vulnerable bargaining posi- tion in a dispute with company $X$. You have to choose whether to negotiate the matter with the person who was your counterpart in this exercise or with a different, unknown executive from the company. Would you choose to negotiate with the person who was your counterpart today over a typical executive from the company?" $(1=$ prefer typical executive $;=$ prefer my counterpart).

\section{Results}

Pre-negotiation questions. We expected schmoozers and nonschmoozers to differ in their feelings about opponents and hence in plans for the negotiation. Dyad means of the ratings on the seven dimensions of feelings about opponents were submitted to a principalcomponents analysis with varimax rotation. An elbow test revealed one major factor (accounting for $37 \%$ of the variance), which corresponded to the rapport construct. We formed a scale by averaging items that loaded heavily on the factor, selected by the criteria of loading greater than .5 or less than .5 on this factor and not on others. The mean of the ratings for cooperative, open, positive, and competive (reverse-scaled) formed a scale with an interitem reliability of .77. As can be seen in Table 2, schmoozers reported significantly higher feelings of rapport $(M=5.34)$ than nonschmoozers $(M=3.78), F(1,54)=17.99, p<.001$.

As can be seen in Table 2, schmoozers set lower reservation prices $(M=1,248)$ than nonschmoozers $(M=1,299), F(1,52)=7.66$, $p<01$. It is important to note, however, that schmoozers did not set lower aspiration levels $(M=1,675)$ than nonschmoozers $(M=1,621)$, $F(1,54)=1.31, p=.26$. This pattern is consistent with the rapport explanation but not the alternative interpetation that schmoozing simply increases positive expectancies about one's outcome. Dyad rapport was negatively associated with the average reservation price $(r=$

\footnotetext{
${ }^{5}$ As these terms were used in participants' negotiation classes, a reservation price is one's lower limit of acceptable deals. Although from an economic-return-maximization perspective this ought to be based on one's best alternative, psychological concerns such as pride, reputation, or fairness often lead negotiators to set a lower limit with an opponent that is higher than they would be able to achieve elsewhere. An aspiration level is one's desired target outcome, a goal to shoot for.
} 
Table 2

Effects of Schmooze Manipulation on Pre-Negotiation Measures (Study 2)

\begin{tabular}{|c|c|c|c|}
\hline Behavior variable & $\begin{array}{l}\text { No schmooze } \\
\quad(n=27)\end{array}$ & $\begin{array}{l}\text { Schmooze } \\
(n=29)\end{array}$ & $\begin{array}{c}\text { Significance } \\
\text { level }\end{array}$ \\
\hline \multicolumn{4}{|l|}{ Attitude toward opponent } \\
\hline Competitive (reversed) & 5.48 & 4.59 & $*$ \\
\hline Cooperative & 4.07 & 5.02 & $*$ \\
\hline Engaged & 4.83 & 4.79 & $n s$ \\
\hline Indifferent & 2.48 & 2.79 & $n s$ \\
\hline Open & 4.17 & 4.97 & $*$ \\
\hline Positive & 4.80 & 5.29 & $*$ \\
\hline Sympathetic & 2.83 & 3.50 & $\dagger$ \\
\hline Index: Rapport & 3.78 & 5.34 & $* * *$ \\
\hline Plans for negotiation & & & - \\
\hline Reservation price & 12,993 & 12,483 & $*$ \\
\hline Aspiration level & 16,209 & 16,753 & $n s$ \\
\hline
\end{tabular}

$-.29, p<.05)$. Rapport reduced the tendency to set a reservation price above one's alternative to defend against the possibility of "losing" to one's opponent. From an economic standpoint, the schmooze manipulation made negotiators more rational-more willing to accept agreements in the range of 1,250 to 1,300 , which dominated their alternative.

Economic outcome. We examined the binary variable of impasse as well as the continuous variable of joint points, although the tight bargaining zone severely restricts variance in joint points. Not surprising, given the tight bargaining zone, half of the negotiator dyads failed to come to an agreement; in other words, the overall impasse rate was $50 \%$. Nonschmoozers impassed at a higher rate $(60.7 \%)$ than schmoozers $(40.6 \%)$, although this difference reached only a marginally significant level, $p<$ .10 (Fisher's exact test). And, rapport was negatively associated with impasse $(r=-.28, p<$ $.05)$. Similarly, in joint points, schmoozers $(M$ $=2,526$ ) did better than nonschmoozers $(M=2,484)$, although this difference fell short of significance, $F(1,58)=2.09, p=.15$, reflecting in part the range restriction on the variable. ${ }^{6}$

Social outcome. Ratings of the 10 dimensions of feelings toward the opponent were submitted to the same principal-components extraction technique as described above. The first dimension, accounting for $59 \%$ of the variance, we labeled positive feelings. A scale was computed from means of ratings for friendly, pleas- ant, positive, sensitive, warm, and cold (reversescaled). Interitem reliability was high $(\alpha=.92)$. Next, the six dimensions of perceived trustrelated characteristics were submitted to the same technique. All items loaded on the first factor, which accounted for $71 \%$ of the variance. We called this factor perceived trustworthy character. A scale formed by averaging the ratings (with reverse-scored ratings for deceptive, secretive, and selfish) had a high interitem reliability $(\alpha=.90)$. Finally, the two items comparing expected working relationship were highly intercorrelated and were averaged to form a summary variable $(\alpha=.91)$, called working relationship, for the final facet of social outcome. As can be seen in Table 3, the general effect was that schmoozers had better social outcomes than nonschmoozers. This was statistically significant for the general measure of positive feelings, $F(1,54)=4.92, p<.05$, as well as for the more specific measure of working relationship, $F(1,54)=4.65, p<.05$, although it fell short of significance for the measure of perceived trustworthy character,

\footnotetext{
${ }^{6}$ Further insight comes from the correlations shown in Table 5, where one can see that the best predictor of a dyad's joint points was a low aspiration level, which is unusual because generally high aspirations predict high scores. Presumably in this tight bargaining zone, very high aspirations begot frustration and ultimately impasse. Hence, a slightly less tight bargaining zone might have prevented this complication, which obscured the hypothesized effect of the manipulation on impasse.
} 
Table 3

Effects of Schmooze Manipulation on Social Outcome Measures (Study 2)

\begin{tabular}{|c|c|c|c|}
\hline Behavior variable & $\begin{array}{l}\text { No schmooze } \\
\quad(n=27)\end{array}$ & $\begin{array}{c}\text { Schmooze } \\
(n=29)\end{array}$ & $F$ \\
\hline Positive feelings $(\alpha=.92)$ & 3.45 & 4.48 & $4.92 *$ \\
\hline Cold (reversed) & 4.67 & 5.33 & $2.84 \dagger$ \\
\hline Friendly & 3.61 & 4.55 & $6.43^{*}$ \\
\hline Pleasant & 3.83 & 4.55 & $3.85 \dagger$ \\
\hline Positive & 3.52 & 4.45 & $6.50^{*}$ \\
\hline Sensitive & 3.15 & 3.57 & 1.56 \\
\hline Warm & 3.04 & 3.48 & 1.49 \\
\hline Perceived trustworthy character $(\alpha=.90)$ & 3.84 & 4.77 & 2.62 \\
\hline Deceptive (reversed) & 4.37 & 4.86 & 1.30 \\
\hline Secretive (reversed) & 3.80 & 4.29 & 1.89 \\
\hline Selfish (reversed) & 3.94 & 4.07 & 0.14 \\
\hline Fair & 3.37 & 3.87 & 1.71 \\
\hline Sincere & 3.48 & 3.95 & 1.39 \\
\hline Trustworthy & 3.44 & 3.97 & 1.56 \\
\hline Working relationship $(\alpha=.91)$ & 3.84 & 4.78 & $4.65^{*}$ \\
\hline "We would work together smoothly" & 4.13 & 5.10 & $5.94 *$ \\
\hline "I'd prefer to negotiate with this person" & 3.56 & 4.45 & $3.15 \dagger$ \\
\hline
\end{tabular}

$F(1,534)=2.62, p=.11$, perhaps because these items were more pejorative than the others. As can be seen in Table 4, these three facets of social outcome were highly correlated $(>.5)$, so they are probably best interpreted as redundant measures of the same basic construct, the positivity of negotiators' impressions of each other.

Finally, to test our interpretation that rapport is the mechanism through which the schmooze manipulation has its effects, we conducted a path analysis to determine whether rapport mediates the effect, according to the criteria of Baron and Kenny (1986). A prerequisite for mediation is that the independent variable predicts the putative mediating variable (rapport) and the dependent variable (positive feelings), which we have already seen to be the case in the correlations of Table 4. The more stringent criterion involves a comparison of regression models to check that the effect of the independent variable runs through the mediating variable. Table 5 shows that the beta coefficient on the independent variable (schmooze condition) is reduced from $.315(p<.05)$ to $.08(p>.05)$ when the putative mediating variable (rapport) is entered as a simultaneous predictor in the regression model (compare coefficients in Equations 1 and 3). Yet the rapport variable coefficient in the simultaneous model (.47) is not appreciably reduced from its level as a lone predictor (.53; compare coefficients in Equations 2 and 3). This finding that the unique variance is associated with the mediating variable of rapport supports the prediction that the effect of the schmooze condition on positive feelings runs through the mechanism of rapport.

Overall, the results of Study 2 provide clear support for the hypothesis that social lubrication can improve outcomes in EML negotiation through the mechanism of increased felt rapport between negotiators. Although the effect on the economic outcome measure reached only marginal levels of significance, social outcome measures, which most directly tap the hypothesized process of negotiators forming negative personal impressions and withdrawing trust, were significantly affected by the manipulation. The social outcome of negotiations (mutual feelings, perceptions, and expectations) often has more far-reaching consequences than the economic outcome. This result becomes quite impressive when one remembers that the manipulation was simply a 5 -min phone call before a negotiation process that took, in many cases, a full week to complete. The rapport measure, taken before the negotiation began, statistically mediated the effect of the manipulation on the outcome measures. Unlike in past studies, where the rapport measures were taken after the 
Table 4

Intercorrelations Among Key Variables in Study 2

\begin{tabular}{|c|c|c|c|c|c|c|c|c|}
\hline Variable & 1 & 2 & 3 & 4 & 5 & 6 & 7 & 8 \\
\hline \multicolumn{9}{|l|}{ Independent variable } \\
\hline 1. Schmooze condition & - & .500 & -.351 & .154 & .187 & .289 & .217 & .282 \\
\hline$p$ & & .000 & .008 & .257 & .153 & .031 & .111 & .035 \\
\hline$n$ & 60 & 56 & 56 & 56 & 60 & 56 & 55 & 56 \\
\hline \multicolumn{9}{|l|}{ Mediating or processing variables } \\
\hline 2. Rapport & & - & -.293 & -.010 & .254 & .527 & .427 & .304 \\
\hline$p$ & & & .028 & .942 & .058 & .000 & .001 & .023 \\
\hline$n$ & & 56 & 56 & 56 & 56 & 56 & 55 & 56 \\
\hline 3. Reservation price & & & - & .301 & -.358 & -.243 & -.268 & -.272 \\
\hline$p$ & & & & .024 & .007 & .071 & .048 & .043 \\
\hline$n$ & & & 56 & 56 & 56 & 56 & 55 & 56 \\
\hline 4. Aspiration level & & & & - & -.235 & .042 & -.154 & -.053 \\
\hline$p$ & & & & & .082 & .758 & .262 & .698 \\
\hline$n$ & & & & 56 & 56 & 56 & 55 & 56 \\
\hline \multicolumn{9}{|l|}{ Dependent or outcome variables } \\
\hline 5. Joint point score & & & & & - & .380 & .590 & .679 \\
\hline$p$ & & & & & & .004 & .000 & .000 \\
\hline$n$ & & & & & 60 & 56 & 55 & 56 \\
\hline 6. Positive feelings & & & & & & - & .597 & .573 \\
\hline$p$ & & & & & & & .000 & .000 \\
\hline$n$ & & & & & & 56 & 55 & 56 \\
\hline 7. Perceived trustworthy character & & & & & & & - & .871 \\
\hline$p$ & & & & & & & & .000 \\
\hline$n$ & & & & & & & 55 & 55 \\
\hline 8. Working relationship & & & & & & & & - \\
\hline$p$ & & & & & & & & \\
\hline$n$ & & & & & & & & 56 \\
\hline
\end{tabular}

Note. Schmooze condition is a dummy variable for lubrication manipulation (schmooze $=1$, no schmooze $=0$ ). Other measures reflect dyad means.

negotiation session had ended or where the rapport measure was taken during the same brief experimental session, this finding clearly indicates the direction of causality. Interactions that began with a higher level of rapport, as a function of the brief required schmoozing session, proceeded on a different path than interactions that began at a lower level of rapport.

\section{General Discussion}

The contributions and limitations of the current research can be discussed first in terms of

Table 5

Regressions Testing Mediation of Condition Effects on Postnegotiation Social Outcome by Rapport

\begin{tabular}{lccc}
\hline & \multicolumn{3}{c}{ Regression equation } \\
\cline { 2 - 4 } Variable & 1 & 2 & 3 \\
\hline Independent variable: Lubrication & $.315^{*}$ & & .080 \\
Mediating variable: Pre-negotiation rapport & & $.527^{* * *}$ & $.470^{* * *}$ \\
$\quad$ Adjusted $R^{2}$ & .083 & .264 & .237 \\
$F$ & 5.96 & 20.73 & $9.55^{* * *}$ \\
$d f \mathrm{~s}$ & $(1,54)$ & $(1,54)$ & $(2,53)$ \\
\hline
\end{tabular}

Note. Cells show beta statistic for regression coefficients. For lubrication, schmooze $=1$ and no schmooze $=0$. $* p<.05$. **** $p<.0001$. 
testing theory and second in terms generating insights about the practical problem of conducting successful e-mail negotiations. The current studies are among the first studies to have focused on the process dynamics that are evoked by the e-mail medium in negotiation interactions; the current findings add to the research program on rapport and cooperation in conflict in several ways. First, the current work used a novel and elegant method (predictions about reservation prices as opposed to aspiration levels) for separating the rapport effect from the alternative interpretation of positive expectancies. Prior studies (Drolet \& Morris, 2000) also teased apart these two potential mechanisms but did so using different methods. Second, the current work goes far beyond prior work in establishing that small manipulations related to rapport have lasting effects-a 5-min conversation had dramatic effects after a week of e-mail negotiating. Finally, the current work goes beyond prior work in that it clearly measured the mediating construct, rapport, prior to the start of any negotiation so that the causal direction underlying its association with outcome measures is unambiguous.

In the spirit of this special issue, the current research also speaks to a practical question: How should people effectively make use of the Internet-enabled communications technology when negotiating deals and disputes? An often heard maxim, supported by the results of Moore et al. (1999), is that e-mail is best used in negotiating with people with whom one already has a relationship. Indeed there are many theories of trust based on the notion that prior relationships or common group memberships provide assurance and enable cooperation (Brewer \& Kramer, 1985). However, negotiations often occur at the start of business relationships between geographically distant parties. The greatest advantage in using e-mail, in terms of saved travel costs, would be gained in such cases, yet in such cases there is often no basis of trust from prior ties. The current findings suggest that a simple preliminary act, a brief phone call, would greatly improve the outcomes to be expected in such cases from an e-mail negotiation.

In many organizations, people spend a high fraction of their time schmoozing rather than working. In the manner of our economist cousins, we can draw on the current hypothesis to account for this ("to prove possible in theory what is already known to exist in reality"). Moreover, it helps us understand why eliminating schmoozing is often a bad idea. Some companies have taken dramatic steps to cut out what they regard to be superfluous conversation and productivity killers only to find that doing so results in particularly negative consequences. For example, a Silicon Valley company cut out all schmoozing by eliminating its traditional Monday morning face-to-face meetings and attempted to get real business done through timesaving, cost-efficient e-mail. The result was that both e-mails and the occasional emergency face-to-face meetings became very tense and upsetting, and eventually the company switched back to its regular meetings (Schrage, 1995). In sum, schmoozing greases the wheels of sociality and commerce, allowing relationships and deals to develop despite the friction involved in negotiations.

\section{Limitations and Future Directions}

We can distinguish several limitations of the current studies in their ability to provide academic theory-relevant insights and several limitations in their ability to provide practical recommendations. In terms of scientific limitations, Study 1 did not involve a perfectly unconfounded manipulation in that negotiators in face-to-face and e-mail conditions were given different amounts of time in which to complete the negotiation. Although negotiators in both conditions undoubtedly felt time pressure to complete the deal, it is possible that the amount of time pressure was different for negotiators in the two conditions and that this may explain some differences in the content of negotiations.

There are some limitations to the manipulation in Study 2 as well. Negotiators in the schmooze condition differed in several ways other than having exchanged personal information. One is that they had a photograph; another is that they had made a phone call. We could have given this information to the nonschmooze condition, too (taking the risk that it might lead them to schmooze during their e-mail negotiation), and a replication of the study with this change would be useful. Also, we could have had nonschmoozers make some other kind of telephone call or make a call to schmooze with someone other than their opponent. This would 
control for the positive emotions created by schmoozing qua schmoozing.

Another possible way to add social lubrication to a long-distance electronic negotiation is to conduct part of the negotiation in the synchronous mode of instant messaging rather than the asynchronous mode of e-mail message exchange. Instant messaging may allow more informality, more questions of clarification, more checking that the other is on the same wavelength before proceeding.

\section{References}

Arunachalam, V., \& Dilla, W. (1995). Judgment accuracy and outcomes in negotiation: A causal modeling analysis of decision-aiding effects. Organizational Behavior and Human Decision Processes, 61, 289-304.

Baron, R. M., \& Kenny, D. A. (1986). The moderator-mediator variable distinction in social psychological research: Conceptual, strategic, and statistical considerations. Journal of Personality and Social Psychology, 51, 1173-1182.

Barsness, Z., \& Tenbrunsel, A. E. (1998, June). Technologically-mediated communication and negotiation: Do relationships matter? Paper presented at the International Association of Conflict Management conference, College Park, MD.

Bazerman, M. H., \& Brett, J. M. (1997). El-Tek negotiations case. Dispute Resolution Research Center, Kellogg Graduate School of Management, Northwestern University.

Brewer, M. B., \& Kramer, R. M. (1985). The psychology of intergroup attitudes and behavior. Annual Review of Psychology, 36, 219-243.

Croson, R. T. A. (1999). Look at me when you say that: An electronic negotiation simulation. Simulation and Gaming, 30, 23-37.

Drolet, A. L., \& Morris, M. W. (2000). Rapport in conflict resolution: Accounting for how nonverbal exchange fosters cooperation on mutually beneficial settlements to mixed-motive conflicts. Journal of Experimental Social Psychology, 36, 26-50.

Kiser, K. (1999). The new deal. Training, 36(10), $116-126$.

Moore, D. A., Kurtzberg, T. R., Thompson, L., \& Morris, M. W. (1999). Long and short routes to success in electronically-mediated negotiations:
Group affiliations and good vibrations. Organizational Behavior and Human Decision Processes, 77, 22-43.

Morris, M. W., \& Keltner, D. (2000). How emotions work: An analysis of the social functions of emotional expression in negotiations. Review of Organizational Behavior, 22, 1-50.

Morris, M. W., Larrick, R. P., \& Su, S. K. (1999). Misperceiving negotiation counterparties: When situationally determining bargaining behaviors are attributed to personality traits. Journal of Personality and Social Psychology, 77, 52-67.

Poole, M. S., Folger, J. P., \& Hewes, D. E. (1987). Analyzing interpersonal interaction. In M. E. Roloff \& G. R. Miller (Eds.), Interpersonal processes: New directions in communication research. Sage annual reviews of communication research (Vol. 14, pp. 220-256). Newbury Park, CA: Sage.

Poole, M. S., Shannon, D. L., \& DeSanctis, G. (1992). Communication media and negotiation processes. In L. L. Putnam \& M. E. Roloff (Eds.), Communication and negotiation: Sage annual reviews of communication research (pp. 46-66). Thousand Oaks, CA: Sage.

Purdy, J. M., Nye, P., \& Balakrishnan, P. V. (1997, August). The impact of communication media on negotiation outcomes. Paper presented at the Academy of Management conference, Boston, MA.

Rangaswamy, A., \& Shell, G. R. (1997). Using computers to realize joint gains in negotiations: Toward an "electronic bargaining table." Management Science, 43, 1147-1163.

Schrage, M. (1995). No more teams! Mastering the dynamics of creative collaboration. New York: Currency Doubleday.

Seaberry, J. (2000, January 3). Deals still done face to face in Internet age. The Star Ledger, p. 36.

Thompson, L. (2001). The mind and heart of the negotiator (2nd ed.). Upper Saddle River, NJ: Prentice Hall.

Tickle-Degnen, L., \& Rosenthal, R. (1987). Group rapport and nonverbal behavior. In C. Hendrick (Ed.), Group processes and intergroup relations (pp. 113-136). Beverly Hills, CA: Sage.

Weingart, L., Thompson, L., Bazerman, M., \& Carroll, J. (1990). Tactical behavior and negotiation outcomes. International Journal of Conflict Management, 1, 7-31. 